\title{
MUTIRÃO AUTOGESTIONÁRIO E O CONTEXTO DA EXPERIÊNCIA DEMOCRÁTICA REVISITADO
}

\author{
Edson Miagusko*
}

\begin{abstract}
O artigo trata das trajetórias dos moradores de um conjunto habitacional na periferia de São Paulo produzido por mutirão autogestionário. Esse mutirão ocorreu no contexto da experiência democrática dos anos 80 . A hipótese é de que as formas de sociabilidade e as trajetórias desses moradores, atravessadas pelo discurso da autonomia e participação, são postas em questão: de um lado, a possibilidade de invenção, da produção da casa a partir de uma ação autônoma; e, de outro, a permeabilidade dessa experiência a uma sociabilidade enclausurada pelos limites determinados de fora e de dentro do próprio conjunto. Para tanto, fizemos um conjunto de entrevistas e procuramos não perder de vista o contexto que determina um campo reduzido de possibilidades. Essa perspectiva permite colher não apenas a ação desses movimentos, mas também o modo como as camadas mais pobres da cidade se organizam para o enfrentamento dessa desigualdade social produzida nos espaços urbanos.

PALAVRAS-CHAVE: periferia, mutirão, movimentos sociais urbanos, moradia, cidades
\end{abstract}

\section{INTRODUÇÃO}

Ana mora sozinha num apartamento de dois quartos, sala e cozinha americana num conjunto habitacional da Fazenda da Juta, periferia de São Paulo. ${ }^{1}$ De perto, porém, o conjunto habitacional de Ana não é igual à "banalidade" dos demais. $\mathrm{O}$ prédio foi construído em tijolo aparente e não tem a monotonia de cores da vizinhança.

Aproximando-se, entrando no apartamento e escutando sua fala, observamos que a história do condomínio União da Juta é incomum: das fundações aos apartamentos, da gestão de recursos

* Doutor em Sociologia. Professor Adjunto de Ciências Sociais da Universidade Federal Rural do Rio de Janeiro e pesquisador do Núcleo de Análise de Políticas Públicas (NAPP) da UFRRJ.

Instituto de Ciências Humanas e Sociais. BR-465, km 7. Cep: 23890-000 - Seropedica, RJ - Brasil. emiagusko@ufrrj.br

${ }^{1}$ Aproximadamente 900 mil moradores habitam esses "conjuntos habitacionais de interesse social" na região metropolitana de São Paulo. Desde a década de 1970 210 mil unidades foram construídas, 130.574 unidades pela Companhia Metropolitana de Habitação de São Paulo e 79.270 pela Companhia de Desenvolvimento Habitacional e Urbano do Estado. Em 1999, a COHAB havia produzido $68 \%$ de suas unidades no extremo leste de São Paulo e três outros municípios da região metropolitana (Itapevi, Carapicuíba e Guarulhos) (Meyer, Grostein \& Biderman, 2004, p.66-67). financeiros à assessoria técnica, as obras foram executadas em seis anos pelos próprios moradores, por meio de mutirão autogestionário. A história dos mutirantes é de, no mínimo, oito anos, se contabilizarmos desde a formação da demanda a partir dos diversos grupos de origem ${ }^{2}$ dos movimentos de moradia até os dias atuais. ${ }^{3}$

A Fazenda da Juta não lembrava um bairro quando Ana pôs os pés pela primeira vez na terra. Hoje, o entorno é diferente. Mas Ana, ao contrário do momento em que reivindicava melhorias para a Juta se transformar em bairro, do período em que se esforçava diuturnamente para estimular as famílias a acelerarem o cronograma das obras, das

2 É através dos grupos de origem que a Associação Sem Terra Leste 1 e suas associações filiadas organizam e selecionam a demanda. Todos que queiram participar do movimento devem entrar nos grupos de origem, em geral organizados em torno de paróquias da Igreja Católica. O grupo de origem é a porta de entrada para o movimento e o objetivo de todo participante é sua seleção para algum mutirão, conforme a conquista de projetos de habitação junto aos órgãos públicos.

${ }^{3} \mathrm{O}$ tempo de participação em algum tipo de movimento de moradia de alguns entrevistados é maior. Eneida, uma de nossas entrevistadas, nos disse que sua primeira ocupação foi em 1982 e desde 1981 se preocupava em conquistar a moradia própria. Eneida tem 46 anos. Do tempo dos grupos de origem até a conclusão das obras do mutirão foram dezessete anos. 
manifestações do movimento e dos projetos dos equipamentos comunitários, pretende retornar para sua terra natal, no estado do Rio Grande do Norte.

O que ocorreu depois do encerramento das obras do mutirão e de ocupação da Juta? Como está o bairro, os mutirantes e o entorno, passado o tempo do mutirão? Esse é o ponto de partida para investigar a história de um conjunto habitacional feito em sistema de mutirão autogestionário na periferia leste de São Paulo. Pode parecer, na atualidade, algo banal, dado que os mutirões foram saudados como "práticas bem-sucedidas" (Bonduki; Saule, 1996), conquistaram prêmios e se instituíram como programas habitacionais. Mas parece que há algo que se transformou, e não é apenas a paisagem física do conjunto habitacional e seu entorno.

Há uma aceleração do tempo para o pesquisador que retorna. $\mathrm{O}$ espanto, porém, não é com a alteração da paisagem e os deslocamentos espaciais, previsíveis num espaço em que existiam apenas conjuntos habitacionais e, hoje, assinala a chegada dos serviços públicos, de hipermercados, de linhas de transporte, de conjuntos habitacionais construídos posteriormente ao fim das obras na União da Juta.

O que impressiona são as histórias dos moradores e sua rápida modificação. São as lideranças principais que saem do conjunto para morar em outro lugar ou fazer o caminho de volta para a terra natal, outras que anunciam um discurso que combina o antigo associativismo comunitário com as necessidades de "parcerias" para obtenção de recursos sempre insuficientes, buscados nos "projetos" financiados por ONGs, igrejas, fundações empresariais ou filantropia privada. São histórias que demonstram que as antigas distinções entre o "nós" e o "eles", que serviam para estabelecer as diferenças entre o conjunto e a vizinhança, agora estão embaçadas ou desfeitas pela presença da violência e o embaralhamento das fronteiras do trabalho e das relações comunitárias.

Revisitar um conjunto habitacional que deve sua existência à ação coletiva dos movimentos de moradia na periferia leste de São Paulo é também revisitar a cena posterior ao momento em que es- sas experiências eclodiram. É visitar uma cena diversa, em que o contexto de privatização do público, retração das políticas sociais e redefinição do papel do Estado reconfiguraram as representações e os sentidos da própria ação desses movimentos e de seus participantes.

Em certo ponto, é isso que faz com que as mesmas ações desencadeadas pelos movimentos de moradia no período anterior tenham desdobramentos diversos no momento atual. Teríamos um “deslizamento semântico" (Arantes, 2004), em que a gramática dos anos 1980 encontraria as transformações dos 1990, e o que aparecia com sinais invertidos se aproximaria discursivamente numa “confluência perversa” (Dagnino; Olvera; Panfichi, 2006, p.16) entre a desresponsabilização do Estado e o "protagonismo da sociedade civil". Assim, o discurso da participação é utilizado como enquadramento da ação heterônoma que interessa ao Estado manter e legitimar.

Ocontextoé diverso daqueleem queeclodiram os principais movimentos de moradia em São Paulo. Esse contexto modificou e transubstanciou as categorias, os diagramas e a forma como os movimentos sociais faziam a experiência, incidindo no debate público e alterando os termos da ação política.

Porém não basta apenas constatar essa mudança. É preciso, para fugir de uma "sociologia da ausência”, procurar remontar esse mundo e os conceitos explicativos. Os próprios entrevistados - e isso fica mais explícito na geração que cresceu depois do mutirão - já não tomam o contexto anterior como parâmetro, e se movem num mundo em que os sentidos do trabalho, da casa, da ação do Estado e a própria sociabilidade se reorganizam de outro modo.

A questão parece ser mais complicada, e o que se percebe nos territórios da pobreza, nos lugares onde se articulam os movimentos de moradia, não é exatamente a ausência do Estado ou de outros atores políticos. O que parece existir é a presença de "programas sociais", de agentes políticos estatais dos três níveis de governo, ONGs, agentes da filantropia privada, religiosa e da caridade, ou seja, não se constata a ausência, e sim a 
presença de diversos agentes num campo de forças complexo.

Portanto, será necessário contar histórias que consigam circular nesse conjunto de experiências sem formas definidas, numa cena pública em que as categorias explicativas mudaram. Narrativa que possa, movendo-se por esses labirintos, com o ato de narrar e nomear, buscar estabelecer seus sentidos.

Este artigo trata das trajetórias dos moradores de um conjunto habitacional na periferia de São Paulo produzido por mutirão autogestionário ocorrido no contexto da experiência democrática dos anos 80. Buscamos argumentar que as formas de sociabilidade desses moradores, atravessadas pelo discurso da autonomia e participação, alteraram-se diante desse novo contexto de desresponsabilização do Estado e alteração das políticas sociais. Para isso, fizemos um conjunto de entrevistas e procuramos não perder de vista o contexto que determina um campo reduzido de possibilidades. Essa perspectiva permite colher não apenas a ação desses movimentos, mas o modo como as camadas mais pobres da cidade se organizam para o enfrentamento dessa desigualdade social produzida nos espaços urbanos.

Este texto, portanto, está dividido em três partes: em primeiro lugar, apresentamos alguns dados para identificar o contexto socioespacial em que se insere o mutirão União da Juta; depois, apontamos algumas questões para a literatura sobre mutirões; e, por fim apresentamos as histórias dos mutirantes após a conclusão das obras nesse novo contexto.

\section{A JUTA VISTA DE CIMA}

O conjunto habitacional União da Juta, cujo nome oficial é Itaquera B- $4,{ }^{4}$ fica em Sapopemba, região sudeste de São Paulo. Em 2000 (IBGE),

${ }^{4}$ Itaquera B-4 é a denominação oficial dada pela CDHU para o conjunto habitacional União da Juta, nome escolhido pelos antigos mutirantes para denominar sua associação e o condomínio inaugurado em 1998. O nome União da Juta será a denominação utilizada no texto.
Sapopemba era o segundo distrito mais populoso de São Paulo, com 523.676 habitantes, perdendo apenas para a Capela do Socorro.

A União da Juta integra uma gleba de 730 mil $\mathrm{m}^{2}$, a Fazenda da Juta, que possui dezessete conjuntos habitacionais e 4.706 habitações construídas em várias modalidades pela Companhia de Desenvolvimento Habitacional e Urbano (CHDU). Desse total 2.806 habitações foram construídas em sistema de mutirão e 1.900 por empreiteiras contratadas pelo governo do Estado. A União da Juta foi o primeiro mutirão executado com recursos do Governo do Estado na Fazenda da Juta.

Na União da Juta, moram 800 pessoas, distribuídas em 160 apartamentos de dois dormitórios e com três tipologias de $60 \mathrm{~m}^{2}$. A obra durou seis anos, entre 1992 e 1998, mas a demanda foi constituída dois anos antes, a partir dos diversos grupos de origem do movimento de moradia na região leste de São Paulo. Apesar do adensamento populacional no distrito, a ocupação do entorno do conjunto habitacional é recente. A vinda dos antigos mutirantes ocorreu quando não havia serviços e equipamentos públicos na União da Juta.

Desde que os mutirantes entraram na terra, muita coisa mudou. A primeira e mais evidente é a existência dos prédios de tijolos aparentes, construídos em sistema de mutirão autogestionário em seis anos e concluídos há dez. A segunda é o entorno. Apesar de inacabado, o que é característica de um bairro em construção, serviços públicos e o pequeno comércio se instalaram no local. A Unidade Básica de Saúde (UBS) apareceu logo após o final das obras, a Escola Estadual Fazenda da Juta demorou mais alguns anos para ser inaugurada e a $3^{\mathrm{a}}$ Companhia do $38 .{ }^{\circ}$ Batalhão da Polícia Militar Metropolitana (BPM/M) foi entregue há quatro anos.

Além dos equipamentos públicos, o conjunto conta com os equipamentos comunitários, resultado da organização das famílias na associação. O centro comunitário é sede da creche conveniada, da padaria comunitária e dos vários cursos do projeto Sonho Jovem que atendem a adolescentes e crianças em situação de risco. 
Segundo os indicadores do Mapa da vulnerabilidade Social de São Paulo (PMSP, 2004), Sapopemba é classificada na situação de média e alta privação socioeconômica. Os principais indicadores que pioram esse desempenho estão na habitação e nas taxas de homicídios entre jovens de 15 a 29 anos. Há trinta e quatro favelas no distrito, e as taxas de homicídio entre jovens é de 112,9 homicídios/100 mil pessoas. O número é elevado em relação à média do município $(93,8)$ e coloca o distrito em quinto lugar nessa faixa etária, se comparado a outros da zona leste. Esse dado determinou o sentido de vários programas de assistência na região e conformou o "problema social" principal e a vocação das associações e organizações comunitárias no atendimento aos jovens e crianças que cometeram crime ou infração, nomeadas como "em situação de risco".

A imagem do bairro é dada pela fama de violento, e é através dos problemas de desagregação familiar ou infraestrutura urbana que ele é retratado no discurso midiático. Esse discurso não se encerra apenas na mídia e constrói o par "problema-diagnóstico" a partir da taxa de homicídios entre jovens, gravidez na adolescência e o número de habitações precárias e favelas, que estabelecem as representações externas do bairro.

Esse discurso-diagnóstico estabelece um círculo vicioso entre o problema social focado, os programas do Estado definidos para enfrentá-lo, o "público-alvo" determinado e os vários discursos (políticos, midiáticos, das ONGs, dos religiosos, dos movimentos de moradia) que apresentam soluções para os problemas locais. Os problemas de infraestrutura urbana e da violência são os temas principais quando o bairro aparece na mídia, cujas matérias parecem estar construídas para apenas comprovar aquilo que já se sabe. Dois artefatos estatísticos são sempre ressaltados: a violência que vitimiza os mais jovens e a gravidez precoce entre adolescentes. Contudo, apesar do sensacionalismo, os ciclos de violência obedecem a certo ordenamento e são expostos na fala de vários de nossos entrevistados, o que mostra um código que ordena a vida, porém, não exposto de maneira clara.
Esse discurso determina na Juta o "efeito de lugar” (Bourdieu, 1998) que bloqueia estratégias, define trajetórias e encerra imagens do lugar e de seus moradores. Nesse aspecto, é entre os jovens que os efeitos aparecem de forma intensa, uma vez que estão distantes do universo de sacrifício dos pais e nascidos nas redes de sociabilidade que permeiam o conjunto. É nesse contexto que buscaremos narrar as experiências encontradas.

\section{MUTIRÃO AUTOGESTIONÁRIO: a história de uma questão}

A questão dos mutirões não é recente, e há diferentes estudos que procuram compreender seus significados (Ronconi, 1995; Felipe, 1997; Guerra, 1998; Sachs, 1999; Barros; Miagusko, 2000; Fortunato, 2002; Arantes, 2000; Carvalho, 2004; Ferro, 2006; Lopes, 2006; Oliveira, 2006; Rizek; Barros, 2006; Carvalho, 2007), analisando desde os programas habitacionais propriamente ditos, ao significado do mutirão como possibilidade emancipatória no projeto participativo, às dimensões da relação entre arquitetos e mutirantes no canteiro, até às políticas de financiamento.

O trânsito entre as várias dimensões do mutirão atravessa um campo de pesquisa no qual os próprios pesquisadores se inserem na prática profissional analisada. Nas Ciências Sociais, o foco é posto nas relações entre os movimentos de moradia, a produção da casa e do projeto participativo, que apontam práticas autônomas e emancipatórias nessas dimensões. A maioria dos estudos destaca o aspecto emancipatório do mutirão, em contraponto às políticas habitacionais impositivas do Estado.

Dos vários ângulos da literatura dos mutirões há uma multiplicidade de interesses de análise. A profusão de estudos, porém, não se livra de certa "mitologia emancipatória" do mutirão autogestionário e até mesmo reproduz uma "fábrica de mitos e noções" sobre suas práticas efetivas (Rizek; Barros, 2006).

O texto de Chico de Oliveira (1976), Crítica 
à Razão Dualista, é um dos precursores da polêmica que estabelecia uma linha de funcionalidade entre sobretrabalho e mutirão, identificando que, ao transferir para os mutirantes os custos de sua reprodução, o mutirão rebaixava o valor da força de trabalho. A constatação de Oliveira decorria de pesquisa sobre condições de habitação dos pobres em Santos, de aspecto intrigante da produção de moradias: a maioria das moradias era construída através de um longo acúmulo de poupança privada das famílias, que economizavam em outros aspectos da reprodução, como alimentação, educação e saúde, para destinar os poucos recursos na construção de suas próprias moradias. Assim, o processo de urbanização e acumulação capitalista se assentava no trabalho extra e na absorção dos custos da habitação pelas famílias de baixa renda e na desobrigação de o capital arcar com os custos de sua reprodução. $E$ isso aparecia através do mutirão nos finais de semana e da poupança privada para a compra dos materiais de construção (Oliveira, 1976).

Por outro lado, o mutirão também aparecia no campo da arquitetura e do urbanismo como crítica ao desenvolvimentismo e repercutia em outros campos da produção intelectual e estética como questionador do projeto moderno a partir da obra de arquitetos como Sérgio Ferro (1977), aos projetos padronizados das habitações populares pelos governos autoritários, ao lugar social do arquiteto e à interação entre movimentos sociais, universidade, luta pela redemocratização e lutas urbanas (Rizek; Barros, 2006).

Ocorre que a autoconstrução aparece pela primeira vez como possibilidade de ordenamento em dois contextos distintos: no contexto nacional, como contraponto às políticas do $\mathrm{BNH}$, centralizadas e direcionadas à classe média no período ditatorial e, portanto, como política empunhada pelos movimentos de moradia, e nas recomendações "participativas" da autoconstrução como solução para o problema de moradia para as camadas mais pobres que o Banco Mundial e o BID faziam em países da América Latina. No Brasil, as políticas alternativas, como o mutirão, questionavam as políticas do BNH no ciclo anterior (Sachs, 1999), excludentes para as camadas de baixa renda tanto no financiamento como nos projetos. Mas, no entorno latino-americano, as políticas de autoconstrução eram estimuladas por organismos internacionais como forma de solucionar o grave déficit habitacional pelos próprios usuários, ou seja, as camadas populares.

Esse aspecto contraditório da política que se pretendia emancipatória será pouco observado naquele momento. Contudo, a alteração do contexto de desresponsabilização do Estado, retração das políticas sociais, ajuste fiscal e "ajuste urbano" (Harvey, 2001) aprofundará essas contradições.

No final dos anos 1980, a partir de experiências pontuais e embrionárias, o mutirão se converte em programa habitacional com arranjo institucional baseado no tripé financiamento do governo, gestão dos recursos pelas associações e responsabilidade das obras por assessorias técnicas.

O cenário será, sobretudo, a cidade de São Paulo, onde havia uma teia complexa de agentes: movimentos de moradia com força de mobilização e enraizados em suas comunidades, assessorias técnicas criadas a partir da interação de arquitetos e outros profissionais com esses movimentos e um governo de esquerda na cidade.

Carvalho (2004) traça essa genealogia e divide os mutirões em "três gerações". O primeiro período é embrionário, com experiências pontuais da primeira geração de mutirões, na administração petista (1989-1992), visto como uma fase heroica; o segundo período corresponde às gestões Paulo Maluf (1993-1996) e Celso Pitta (1997-2000), quando os vários convênios firmados anteriormente são questionados judicialmente, as obras são interrompidas e nenhum novo convênio é assinado; e o terceiro período, dos quatro anos de gestão Marta Suplicy (2001-2004), em que os mutirões deixam de ser prioridade para o governo.

O aspecto relevante da genealogia e classificação das três gerações de mutirões é a importância do contexto como determinante para verificar os sentidos dos mutirões autogestionários que se alteram, ainda que permaneça sua "mitologia emancipatória” (Rizek; Barros, 2006). 
Esse "quase acordo" da literatura especializada sobre o tema leva Carvalho a procurar "contar outra história”, exatamente porque a história contada é feita com poucas variações e sempre retornando à história mítica vista do ângulo do ofício e do encontro entre os movimentos de moradia e uma prática emancipatória do arquiteto comprometido com os movimentos sociais. Em busca dessa "outra história", Carvalho associa a produção habitacional por mutirões com o contexto de retração das políticas sociais nos anos 1990 (Schwarz, 1993). Esse contexto coincide com o avanço da participação popular e de políticas sociais, postas em prática por administrações do campo progressista no mesmo momento em que se ampliam as políticas neoliberais de desresponsabilização do Estado.

Neste contexto, aproximam-se velhas e novas questões sobre os mutirões. A problemática do sobretrabalho reaparece e se agrava pela situação de erosão do mercado de trabalho em vários dos assentamentos e ocupações, em que a relação entre o trabalho mutirante e a excepcionalidade do trabalho formal são condições diretamente relacionadas.

Sobre isso é necessário destacar as questões problemáticas no mutirão. Oliveira (2006), retornando ao tema, quase vinte anos depois, afirma que o conflito se publiciza antes do mutirão, quando os movimentos reivindicam a moradia; mas, quando o mutirão acontece, o conflito se privatiza. Essa privatização do conflito não ocorre porque o mutirante irá construir sua casa, mas porque o trabalho executado se tornará invisível.

Esse trabalho invisível é a questão mais relevante e problemática do mutirão como política habitacional. O trabalho do mutirante não apenas não pode ser mensurado ou contabilizado, como não possui estatuto político ou jurídico. Assim, nos custos finais da produção da moradia por mutirão, o custo do trabalho desaparece. Esse trabalho é invisibilizado pelos órgãos financiadores e pelos movimentos de moradia e não é visto pelos mutirantes como trabalho.

Esse problema aparece na dimensão temporal do mutirão, pois os mutirantes em momento algum são donos do seu próprio tempo e depen- dem sempre de outro que o controla e que detém esse poder (Bessin, 1999). É comum que os mutirões se desenvolvam em vários anos, resultado dos atrasos e sucessivas paralisações nas liberações das parcelas pelos poderes públicos, o que obriga, muitas vezes, as associações a percorrerem os labirínticos corredores do Estado e os mutirantes a absorverem privadamente os custos dos longos anos de duração da obra. Carvalho, ao calcular o investimento das famílias para conclusão das unidades no momento que as obras dos mutirões foram completamente paralisadas no governo malufista e retomadas somente anos depois, aponta um montante de $50 \%$ do valor do financiamento que as famílias investiram para concluir a casa. Esse valor, no entanto, desaparece como valor investido pelas famílias, pois a variável tempo desaparece como valor do trabalho mutirante.

Essa "confluência perversa" (Dagnino; Olvera; Panfichi, 2006) entre uma política do campo da autonomia e da participação com as políticas de ajuste fiscal e retração de direitos configurou o novo quadro em que se inserem os mutirões autogestionários. Além das questões relativas ao sobretrabalho e à invisibilização do trabalho, vem à tona o problema da participação e de sua funcionalização para as políticas de exceção embutidas no mutirão. (Oliveira, 2006)

Mesmo o projeto participativo, relacionado à dimensão do trabalho do arquiteto, da possibilidade de democratização da relação do morador com a casa é relativizado, na medida em que as condicionantes técnicas e o repertório dos mutirantes determinam o campo restrito de possibilidades e tipologias.

O impressionante não é que a passagem sobreviva. O elemento mais perturbador é que sobreviva como realidade agravada pelo contexto político que funcionalizou ainda mais o mutirão como "política de exceção". Assim, podemos dizer que o mutirão se consolida como "boa prática" em contexto de "confluência perversa", em que uma política do campo da autonomia se afirma em sua heteronomia. 


\section{A JUTA VISTA DE BAIXO: a vida depois do mutirão}

O retorno à Juta depois de alguns anos faz com que seja inevitável o estranhamento. A primeira constatação é que o entorno não é mais vazio, e a antiga gleba avança para um processo de ocupação a partir da construção de vários conjuntos habitacionais em modalidades diversas pela CDHU. A segunda constatação é o desencontro de várias pessoas que saíram do conjunto e não moram mais lá. A rotatividade atinge $30 \%$ dos moradores e várias pessoas do núcleo originário de 160 famílias já não residem no local.

Mas o estranhamento principal são as relações estabelecidas com o entorno e dos moradores entre si. O período dos batalhadores que fizeram os apartamentos com as próprias mãos passou para outra fase, em que a "vocação" da associação de construção de casas por mutirão é substituída, gradativamente, pelo trabalho com criança e adolescente, decorrente dos vários programas sociais presentes no bairro e que são dirigidas para esse "público-alvo".

\section{A ideologia do sacrifício}

É a partir da "narrativa do sacrifício" que Ana organiza seu percurso: da decisão em procurar o mutirão para esquecer uma desilusão; da disposição em participar durante três anos, aos domingos, das reuniões do grupo de origem na paróquia São João do Brás com mais de duzentas famílias; do sorteio e ingresso na demanda mais rápida, mas em lugar distante; da entrada na terra, lugar cheio de barro, "deserto", para onde ninguém queria ir; do sacrifício do mutirão, do trabalho pesado no canteiro de obras, das novas responsabilidades diante dos demais mutirantes, ao assumir a coordenação; das idas e vindas da obra, que durou seis anos, de "segunda a segunda" como mutirante, coordenadora e compradora da obra. A narrativa da trajetória de Ana é organizada por esse sofrimento.
Essa “ideologia do sacrifício" parece não ser diferente do apresentado em outros movimentos sociais e da estratégia da autoconstrução realizada por milhões de famílias pobres nas periferias de São Paulo. Entretanto, seus sentidos parecem estar em xeque diante das transformações passadas pela Juta após a conclusão das obras do mutirão. O discurso continua reproduzido pelos filhos dos antigos mutirantes, a geração que viu os pais erguerem a casa onde iriam morar durante seis anos, sem descanso. Mas, ironicamente, a ideologia do sacrifício não se repõe apenas para transmitir a experiência para esses jovens e fabular a "história de luta” do mutirão. A ideologia do sacrifício é utilizada pelos mais jovens como justificativa para serem "donos do próprio nariz" e não darem satisfações para os demais moradores do conjunto:

O pior do pós-moradia é o seguinte: que aqueles 160 que construíram, junto com você, são seus amigos, tem um ou dois que ficam de nariz empinado, mas eles não são tão... Mas o ruim é as cobrinhas [...] As cascavéis... Não dá valor na experiência. Aí o pai e a mãe, não têm mais voz. O pai e a mãe se tornam os tímidos, porque os filhos é que mandam nos pais. (Ana, 2000).

O sacrifício é utilizado pela geração dos filhos para justificar o contrário da experiência anterior. Afinal, os pais construíram o mutirão e pagaram a quota de sacrifício da família e, assim, os filhos não se sentem mais na obrigação de se orientarem por determinados padrões de conduta mais rígidos da vida condominial. E, por outro lado, os "cobrinhas" "mandam nos pais", são "meio autoritários” e não obedecem ninguém. Esse problema geracional parece ter se constituído aos olhos do poder público, das ONGs e da associação como a principal questão social do bairro, o sinal trocado e invertido que associa jovem e problema ou jovem e violência. Os dez anos da União da Juta parecem coincidir com a construção de um problema social, o "problema jovem", como assinalam a finalidade dos programas sociais e os diagnósticos dos indicadores que agravam a vulnerabilidade social do bairro. Problema que embute uma solução pré-concebida. 
Os jovens se associam com a questão do consumo, geração para quem o sacrifício não pode mais fazer sentido:

Não tem, porque a máquina... Esse mundo deles é do jeito deles. $\mathrm{O}$ mundo deles é do jeito da televisão, o que passa lá é o que tá correto. Não quer saber se o pai não tem dinheiro pra comprar um tênis de marca, uma roupa de marca, eles querem aquilo. Se o pai não dá, ele vai roubar. Como é que pode [...] uma pessoa dessas? Não tem jeito. Só pedir a Deus que o proteja, porque outra coisa ninguém pode fazer nã̃o. Eé isso, a coisa tá difícil na vida (Entrevista com Ana, 03/09/2005).

Assim, o elemento geracional é decisivo para compreender as relações estabelecidas na Juta no pós-ocupação. E a creche se torna um observatório privilegiado para compreender essas questões.

\section{A creche como observatório privilegiado do conjunto}

A creche, que já esteve no epicentro das relações com o entorno por ser o primeiro equipamento social que deslocou os limites da comunidade, retorna ao centro para questionar a "vocação" do trabalho da associação de moradores. A partir desse equipamento, podemos ver a Juta e seus moradores desde um observatório privilegiado, no qual se avistam as contraditórias relações do condomínio com o entorno e dos moradores de um conjunto habitacional da periferia de São Paulo feito por mutirão.

A creche é observatório privilegiado da trajetória das famílias do mutirão por ser o primeiro equipamento comunitário no bairro, por receber os filhos dos mutirantes e da vizinhança, pela questão geracional dos filhos e o "descontrole" dos jovens “que não respeitam ninguém”. É da creche também que observamos as intrincadas relações daquilo que transformou a ação pública em programas sociais, mediados pela dimensão comunitária, no contexto do desmanche.

A primeira dimensão diz respeito às tensões e ambiguidades do projeto comunitário. O primeiro momento em que os mutirantes se viram defrontados com a necessidade de estabelecer os limites da comunidade foi por ocasião da decisão de quem seria atendido pela creche nos dias de semana: se apenas os filhos dos mutirantes, ou se as crianças que moravam no entorno do mutirão, nos "predinhos" brancos.

A decisão da maioria foi o atendimento a todos. O discurso do "nós" e "eles" era fortalecido pela organização diferencial dos mutirantes em relação aos vizinhos. Os mutirantes eram organizados politicamente e decidiam tudo em assembleia.

Esse tipo de organização, influenciada pela "ideologia comunitária" da Igreja Católica, se via em posição autônoma em face ao Estado e aos partidos políticos, alternativa à democracia representativa e ao jogo de interesses manifesto no jogo político. A transformação das reivindicações de movimentos, como o de moradia, na luta pelos direitos foi o mote principal que congregou vários tipos de movimentos populares, desde os de moradia até os de saúde, transporte, etc. Contudo a ideologia comunitária teve outro desdobramento. A prioridade dada à identidade da comunidade, do pertencimento ao grupo de origem, ou que se unia para finalidade comum, fez diminuir, nesses grupos, os compromissos gerais e as demandas públicas. Apesar de diferente em relação ao clientelismo, a ideologia comunitária seguiu o padrão dessa forma de fazer política, no que diz respeito aos efeitos segmentadores (Zaluar, 2006, p.210-211). Aquilo que dava o amálgama e a dimensão pública a essas iniciativas das associações não eram as ações em si, por mais virtuosas que fossem. O que lhes conferia a dimensão pública era o contexto de publicização do conflito, em que antigas e novas demandas estavam inseridas e alargavam o espaço mais amplo de possibilidades do avanço da experiência democrática.

Quando o contexto desapareceu, o conjunto dessas experiências sofreu forte questionamento.

No caso da União da Juta, enquanto o mutirão funcionava, a dimensão coercitiva da política impelia a unidade da comunidade. Isso garantiu que $o$ atendimento durante a semana fosse realizado para crianças do entorno. 
No momento que o mutirão se encerra e as famílias entram nos apartamentos, as tensões e ambiguidades do momento da obra se explicitarão e revelarão as tensões entre uma experiência do contexto democrático e uma cena de encolhimento das dimensões publicizantes. É a partir da creche, nascida antes do condomínio, que podemos observar o novo contexto.

Setembro de 2007. Eneida recebe minha visita em domingo ensolarado e vamos para seu apartamento. O dia é propício para uma conversa mais longa. Se fosse durante a semana, precisaria dividir sua atenção com a administração da creche comunitária, da qual é diretora. Subimos os quatro lances de escada e cumprimentamos os moradores no caminho.

O apartamento é arrumado e os móveis estão conservados. O sofá separa a cozinha da sala e, na estante, destacam-se a televisão com tela plana, o DVD, o aparelho de som com luzes de várias cores piscando. No quarto, o computador dá acesso à internet de banda larga e está conectado à impressora ligada.

A insígnia da melhoria de vida não está apenas no acesso ao consumo de eletro-eletrônicos. Eneida, assim como sua filha, conseguiu subir um "degrau" nesse processo de "inclusão" simbólica. A necessidade de adquirir uma formação universitária para desempenhar as tarefas de diretora da creche conveniada fez com que se matriculasse no curso de graduação em pedagogia na Universidade Mogi das Cruzes, concluído em 2003.

Nascida em São Luís, no Maranhão, Eneida morou em Brasília e trabalhou como babá, dos doze aos vinte anos. No retorno a São Luís, perdeu o emprego e resolveu vir para São Paulo para trabalhar como empregada doméstica ou faxineira até se firmar no comércio. Como comerciária, descansava pouco e trabalhava nos finais de semana.

Quando a situação melhorou e se estabeleceu, tomou duas decisões: trouxe a filha e ingressou no grupo de origem do movimento de mora- dia, com a finalidade de sair do aluguel. O primeiro contato de Eneida com o movimento de moradia foi em 1982, a partir de uma ocupação em Itaquera, bairro da periferia leste de São Paulo, em que acampou por quatro meses, em lote próximo ao que hoje é a Avenida Jacu Pêssego. Trabalhava de dia e dormia à noite na ocupação. A pressão do movimento levou a Prefeitura a "entregar os pontos" e destinar lotes para a construção de casas. Contudo, para Eneida não seria daquela vez: sem família e sozinha em São Paulo, não tinha o perfil exigido para ingressar na demanda do programa.

Quando trouxe a filha do Maranhão, era mais experiente e estabelecida. Trabalhava na Mooca e ingressou no grupo de fábrica do movimento de moradia. Foi lá que ocupou a Fazenda da Juta, em 1986, acontecimento que seria considerado o "batismo" da União dos Movimentos de Moradia.

Essa participação lhe garantiu pontos preciosos para entrar na "fila" dos programas e, quando a demanda da União da Juta saiu, Eneida estava no grupo originário.

A reconstituição de sua chegada à diretoria da creche é marcada pela mágoa das lideranças do movimento, de ter sido abandonada, de ver mais solidariedade no "emprego da empresa privada" que no "trabalho coletivo da associação". Não sabia como conduzir a creche, precisou "aprender" um trabalho que, para além de desconhecido, era marcado pela opressão de vida.

Do mutirão falou pouco, apesar de ser da coordenação durante as obras. Sem poder acompanhar o ritmo inicial, desdobrava-se para trabalhar no comércio durante a semana e construir em mutirão aos sábados e domingos. Adotou a estratégia familiar de trazer um primo de São Luís e transformá-lo em suplente para equilibrar as presenças necessárias na obra. A filha pequena não podia trabalhar.

Apesar do papel desempenhado na creche, Eneida só teve dedicação exclusiva à Associação após se desligar do antigo emprego numa loja de varejo. A saída do emprego de dez anos foi cercada de dúvidas e incertezas em relação ao passo seguinte. Eneida foi convidada pelos coordenado- 
res para conduzir a creche conveniada. A tarefa foi vista como "dilema” e "desafio": o dilema era trocar o emprego de dez anos por outro com salário menor e o desafio era encarar um trabalho sem patrão e fruto do "trabalho coletivo" do movimento de moradia.

O momento seguinte é de decepção e desalento diante do "abandono" pelas demais lideranças. Sentiu-se jogada na creche, responsável pelos meandros de uma administração desconhecida e sem suporte das lideranças mais experientes. A mágoa leva à comparação inevitável, à constatação de disparidade de tratamentos e ao "acerto de contas" com o passado:

Tive outra relação com a empresa privada que eu havia construído, que eu não tive aqui. Antes de vir, me perguntaram (no emprego do comércio): - Isso é muito importante pra você? Eu falei: - Isso é muito importante pra mim. - Se é importante pra você nós vamos te liberar com tudo que você tem direito. As pessoas vinham aqui pra saber como eu estava. Eu construí na empresa privada uma relação que eu não construí na associação (Eneida, 08/09/2007).

Eneida vê na chegada à creche o espanto da situação que ela esperava encontrar na empresa privada, mas que acabou encontrando nas disputas internas da associação.

A decepção a levou a se dedicar às questões do condomínio e a minimizar a participação no movimento. Isso a fez olhar o contexto mais próximo dos moradores. A sustentação financeira da creche sempre foi difícil, mas, nos últimos anos alguns recursos parecem ter auxiliado nessa função.

Desde minha última visita, a creche foi toda reformada. Entro nas salas e vejo desenhos expostos, a cozinha com bancada de metal e salas com atribuições específicas para as crianças. $\mathrm{O}$ drama das educadoras e das crianças eram os dias de chuva. O telhado com inúmeras goteiras prejudicava o andamento do aprendizado das crianças. A reforma fez com que esse problema fosse solucionado.

Pergunto se foi a Prefeitura que reformou a creche. Eneida responde que a reforma foi financiada com recursos do Instituto Camargo Correa, que contratou a Escola das Cidades para o projeto da reforma e a ONG FICAS 5 para o assessoramento do projeto pedagógico. Em 2004, a associação foi selecionada pelo Instituto Camargo Correa no "Programa Espaços Educativos" e ficou entre os dez projetos de entidades e associações aprovados, quatro deles na zona leste.

O Instituto financiou a reforma, mas o projeto pedagógico e arquitetônico fazia parte do "pacote" que envolvia também a assessoria da Escola das Cidades na parte arquitetônica e o FICAS na parte pedagógica, além da contratação da empreiteira pela associação.

No texto de apresentação do programa, sabemos também os objetivos e o público-alvo:

O Programa Espaços Educativos tem como sujeito de ação organizações sociais que trabalham com educação de crianças, adolescentes e jovens, na faixa etária de 0 a 18 anos em São Paulo. Atualmente está apoiando financeiramente e tecnicamente 10 organizações. O grupo está finalizando seu primeiro ano no Programa - cada organização está concluindo a elaboração de seu plano educativo e iniciando a construção/reforma do espaço educativo [...]. O principal papel do FICAS no Programa Espaços Educativos é estimular a reflexão conjunta das organizações sobre o uso e gerenciamento dos seus espaços, a partir de suas concepções pedagógicas - trazendo para isso insumos teóricos e vivências práticas. O objetivo é construir um plano estratégico educativo que seja a base para trabalhar os espaços construídos/reformados.

Para receber os recursos do Instituto, foi necessária a readequação do estatuto para o trabalho social com criança e adolescente no lugar do objetivo inicial da moradia, e a readequação do projeto pedagógico assessorado pelo FICAS.

Eneida vê, a partir desse financiamento, um momento que a faz refletir sobre a nova "missão,

${ }^{5}$ No site do FICAS estão os objetivos e o histórico da organização. Trata-se de "organização social sem fins lucrativos" criada em 1997 por um grupo de profissionais "mestres e doutores" de diversas áreas de saber que desejavam compartilhar o conhecimento acadêmico restrito às universidades com pessoas e comunidade que pudessem se beneficiar diretamente disso. Depois de constituir-se inicialmente como associação, segundo o site, o contato com outras ONGs levou o FICAS a perceber que o problema principal era a "gestão": "Afinal, para desenvolver as atividades-fim de forma mais eficiente e gerar um maior impacto social, é necessário saber planejar, captar e gerenciar recursos, elaborar projetos e avaliar seus resultados, entre outras ações gerenciais". A respeito ver www.ficas.org.br 
visão e valores” da União da Juta:

Aí a associação está passando por um processo novo, que é as pessoas trabalharem juntas, que isso não estava acontecendo, discutir a missão, a visão, os valores, quer dizer, estruturando, codificando essa associação para poder futuramente... então agora houve a abertura de estatuto, que veio no novo código civil, teve que mudar o estatuto para estar de acordo com o código, que até então era uma coisa que não íamos mexer (Eneida, 08/09/2007).

O discurso de Eneida incorpora as palavras de uma gestora de organização não-governamental e procura refletir sobre a nova "missão" da associação. Eneida procura adaptar-se à situação em que apenas os recursos públicos não bastarão para manter a creche em funcionamento e já trabalha com o cenário impositivo da necessidade de captação de recursos externos.

A creche vingou porque a "missão" da associação mudou para "atendimento de crianças e adolescentes". Além da creche, os demais projetos sociais têm a marca dessa "especialização". O Projeto Cultural Sonho Jovem, financiado com recursos da Prefeitura, atende a 270 crianças e jovens, de seis a quinze anos, nas oficinas de capoeira, dança, violão, etc. O Programa Agente Jovem do Governo Federal atende a quarenta jovens de quinze a dezoito anos em medidas socioeducativas. Os dois programas são gerenciados pela Secretaria Municipal de Assistência e Desenvolvimento Social.

Trabalham na creche onze funcionários, responsáveis pelo atendimento de sessenta crianças de um a quatro anos de idade. Há, além da diretora, uma coordenadora pedagógica, cinco educadores, uma auxiliar de enfermagem, uma cozinheira, uma auxiliar de cozinha e uma faxineira. O repasse da Prefeitura é de 218 reais por mês por criança, e são esses recursos que devem pagar as professoras e funcionárias, alimentar as crianças, comprar os materiais escolares necessários e assegurar a infraestrutura básica. Eneida afirma que os recursos são insuficientes e, invariavelmente, a creche faz festas e bingos para garantir o funcionamento. Mas essa estratégia está se esgotando por sua recorrência:
E aí a gente se matava, fazia festa, fazia bingo. Mas só os profissionais. Porque aí chega uma hora ou ele faz o pedagógico ou ele vai fazer festa. Vale a pena manter o trabalho assim para mostrar para o movimento? Pode ser que eu esteja totalmente errada, mas eu acredito que não é dessa forma (Eneida, 08/09/2007).

A creche funciona "no vermelho" com os recursos insuficientes do convênio da Prefeitura. Eneida reclama, mas parece se conformar com essa dupla tarefa de "administrar" o equipamento comunitário e ser obrigada a trazer recursos para a manutenção da creche:

...vamos deixar de lado um pouco nossos direitos
para manter a creche. Porque o sindicato deu
$10 \%$ de aumento e nós vamos ficar com nosso
salário de 2006. Nós vamos ganhar isso, por en-
quanto, para não fechar a creche. Tendo aumen-
to público que o secretário não definiu, tem um
fórum e eu represento a associação. Porque você
tem que se desdobrar em direcionar a creche e ir
atrás de todas essas coisas que você está envolvi-
do. Porque não adianta ir só para o movimento
(Eneida, 08/09/2007).

Nos últimos anos, modificações na Lei de Diretrizes de Base (LDB) alteraram o estatuto das creches conveniadas, do campo da assistência social para a educação infantil. Isso estabeleceu metas de qualificação para seus profissionais, como a exigência de diploma de curso superior em Pedagogia, ao contrário do período anterior, em que não havia obrigatoriedade de diploma para cuidar das crianças. Isso acarretou, do ponto de vista da administração da creche, duas questões: em primeiro lugar, a exigência de diploma levou várias das educadoras a retornarem aos estudos em faculdades privadas; em segundo lugar, a qualificação maior passou a demandar um corpo de funcionários com salários maiores.

Inevitável não perceber, na Juta, movimento de cunho mais geral, de "filantropização da pobreza" que percorre os territórios da cidade, marcado não apenas pela dimensão da pobreza das periferias, mas pelo tratamento a partir de organizações não-governamentais e da filantropia empresarial. Mas, mais que isso, é como se o par problema-diagnóstico demandasse uma intervenção pre- 
viamente construída, cujo "horror à realidade" assume ares de realismo, procurando administrar carências e sociabilidades violentas a partir de uma racionalidade gerencial (Paoli, 2007). Nessa engrenagem, as possibilidades se estreitam para quem está na ponta do atendimento.

Assim, há certa inexorabilidade no discurso de Eneida, que percebe a diferença do trabalho anterior do mutirão e se conforma com os laços de solidariedade cindidos e a nova perspectiva do trabalho social:

... quem não entrar nesse sistema, nessa proposta de trabalho, que a gente tem essa relação com os projetos, fazer as discussões se encontrarem, vai chegar uma hora que não aguenta, vai acabar saindo. Não que a gente queira que seja assim. Mas a própria pessoa vai acabar saindo (Eneida, 08/09/2007)

Olhado de baixo, tem-se a dimensão de como a diretora da creche faz suas "escolhas" num contexto cada vez mais restrito. A possibilidade de garantir estrutura mínima para o funcionamento da única creche do condomínio não é obrigação do Estado, mas deve ser captada externamente, na concorrência com outras associações que disputam entre si a "missão" que mais se adequa às exigências do organismo financiador. Essa concorrência pelo melhor projeto que trará o melhor resultado pontual, porque analisado de forma segmentada e fragmentada, reduz os horizontes possíveis e obriga Eneida a se movimentar num campo de encolhimento das possibilidades.

Eneida reflete sobre isso e não acha o cenário alentador. Mas parece não ter escolhas: ou é aceitar ou é fechar o projeto. $\mathrm{O}$ fato de a creche ser o primeiro equipamento comunitário do movimento de moradia faz com que se agregue relação de voluntariado e missão mais efetiva, pois pelo equipamento passaram os filhos dos mutirantes e agora passam seus netos. Para manter a creche, os funcionários fazem rifas, festas, bingos e aceitam até receber salário menor que o dissídio instituído pelo contrato coletivo da categoria. As "escolhas" ocorrem num contexto de encolhimento, em que as possibilidades são poucas para quem está na ponta do atendimento e precisa enfrentar as condições precárias de trabalho e infraestrutura, ausência de recursos financeiros e a explosão de demanda resultante da precária presença do Estado nas áreas sociais, particularmente nas periferias urbanas. Um trabalho que, como definiu Bourdieu (1998), é “a mão esquerda do Estado” e que, nesse caso, é até impreciso: a creche de Eneida não é um equipamento do Estado, apesar de os recursos provirem de um convênio com a Prefeitura.

Esse encolhimento de possibilidades obriga, assim, à mudança de “missão” da associação. Essas funções já haviam mudado com o final do mutirão. A fala de Eneida revela o quanto de coerção existia na comunidade que se organizava para o mutirão:

\begin{abstract}
Então todas as assembleias, a regra era cada um de nós estar lá. Se nós não estávamos, nós tínhamos uma falta; depois de 3 faltas tinha exclusão, perdia a casa. Tinha regras que fazia você estar na decisão como um sócio. Quando isso acabou, não tinha mais regra. Por que eu iria estar na assembleia da associação? Eu não tenho mais nada a ver com isso, a minha casa já está aqui. Eu vou se eu quiser, não tenho mais obrigação.[...] O que me motivava a continuar participando da associação, se o principal motivo eu já tinha? Eu já tenho assinado o meu contrato com a CDHU, não tinha mais contrato com a associação, não tinha mais um regulamento interno para me obrigar a ir (Eneida, 08/08/2007).
\end{abstract}

A participação política tinha dimensão quase obrigatória, pois a ausência às assembleias poderia representar a perda da vaga no mutirão e do apartamento. Quando as obras se encerraram, a participação reduziu. Para Eneida, era mais que isso. A finalidade e o objetivo da fundação da associação - fazer apartamentos em sistema de mutirão - havia se encerrado. Assim, o estatuto e a missão da associação deveriam mudar.

Essa modificação não foi rápida. A mudança nos estatutos foi realizada recentemente e incorporou a ideia de ampliação do universo de associados. Anteriormente, eram "sócios" apenas a demanda final do mutirão, os 160 moradores. Alguns deles ainda moram no condomínio, outros não. A alteração amplia a possibilidade de associ- 
ação para quem concordar com o estatuto. De um ângulo, podemos ver a ampliação para o entorno, além dos limites do condomínio, o que significa uma mudança significativa, à medida que a associação deixa de ser orgânica da Associação SemTerra Leste 1 e passa a representar outros moradores sem ligação com o movimento de moradia, apesar de isso não estar claro para os moradores do conjunto.

Mas, por outro lado, esse movimento inserese em outro. A alteração do estatuto prevaleceu devido à necessidade de captação de recursos externos para manter os trabalhos nos equipamentos comunitários. O convênio firmado com o Instituto Camargo Correa para a reforma do prédio da creche exigiu a alteração da cláusula do estatuto, pois o equipamento só seria reformado se atendesse às exigências de enquadramento do financiador.

Mais que a mudança estatutária, a creche deve, na visão de Eneida, alterar sua missão. A finalidade de construir apartamentos se encerrou. A condição de existência da associação passa a ser a inserção na vocação do trabalho na região da Fazenda da Juta e Sapopemba: o trabalho com crianças e adolescentes. Assim, a nova missão é o atendimento desse público-alvo para conseguir os financiamentos necessários para sua manutenção. Por isso, o papel da creche é preponderante, pois atua diretamente com esse "público-alvo". ${ }^{6}$

\section{CONSIDERAÇÕES FINAIS}

Após quase uma década do final do mutirão União da Juta, podemos observar uma cena diver-

${ }^{6}$ A percepção das crianças e jovens como um problema social que deve ser esquadrinhado, respondido e enfrentado aparece de forma ainda mais "nítida" para os agentes sociais e para as lideranças dos movimentos de moradia na medida em que são ampliadas as estatísticas e se destacam como elemento principal de vulnerabilidade social na região a taxa alta de homicídios entre jovens de15 a 24 anos e a taxa de gravidez precoce entre as adolescentes. No entanto, é preciso reserva sempre com esses dados. A explicação fácil que embute a solução para o problema e cria uma parafernália de respostas é, muitas vezes, estimulada pelo discurso midiático sensacionalista, que cria artefatos estatísticos e destaca somente os aspectos mais perversos em determinadas regiões, aprofundando o estigma que recai sobre elas. sa. O mutirão ainda continua como uma espécie de "mito fundador", entre os moradores do conjunto habitacional, do momento onde o sacrifício e o sobretrabalho eram compensados pelo objetivo comum da construção da casa e em acabar o mais rápido possível a obra.

As histórias narradas do mutirão, porém, se estruturam a partir do sofrimento para alcançar um objetivo maior: o apartamento próprio. Não se tem "saudades" dessa época, mas do momento no qual "o coletivo era maior que o indivíduo". Também a discussão dos mutirantes sobre os equipamentos comunitários, vistos em perspectiva, se materializou: a chegada de equipamentos públicos como a escola, o posto de saúde, a polícia e os chamados projetos sociais e culturais demonstram uma presença significativa do Estado (e não sua ausência) como indutor da produção habitacional na Fazenda da Juta e nos serviços públicos que chegam, mesmo que precariamente, nesse lugar da cidade.

Contudo, a transformação do contexto sociopolítico em que os moradores da Juta estão situados mudou sua apreensão sobre o trabalho, a política e os fez buscar estratégias de sobrevivência em que as próprias escolhas são reduzidas. É isso que está presente na ambiguidade da ideologia comunitária e na mudança de "vocação" da associação já na fase dos projetos sociais pós-mutirão.

Ao retornar à União da Juta - uma associação de construção de casas por mutirão, criada no contexto das grandes ocupações de terra na zona leste de São Paulo no final dos anos 1980, mas com as obras concluídas em 1998 e o pós-ocupação nesses últimos dez anos - pudemos observar que as características iniciais da associação mudaram. Encontramos a convivência com um mundo em que os recursos públicos são insuficientes para financiar as políticas públicas e que a filantropia privada, a "onguização" do trabalho social, o par problema-diagnóstico ordenam agora a ação dessas associações populares nas periferias precárias de São Paulo.

Esse encontro entre políticas configuradas no contexto em que eclodiram experiências participativas com um novo momento de políticas 
de ajuste fiscal e retração de direitos reconfigurou o quadro dos mutirões autogestionários e definiram um novo solo por onde circulam as trajetórias, as formas de sociabilidade a ação política dos antigos mutirantes.

(Recebido para publicação em março de 2010) (Aceito em agosto de 2010)

\section{REFERÊNCIAS}

ARANTES, P. E. Zero à esquerda. São Paulo: Conrad Editores do Brasil, 2004.

Arquitetura nova: Sérgio Ferro, Flávio Império e Rodrigo Lefèvre, de Artigas aos mutirões. São Paulo: Editora 34,2000

ARENDT, H. Homens em tempos sombrios. São Paulo Companhia das Letras, 1999.

BARROS, J. S.; MIAGUSKO, E. Mutirão da Juta: do “fim do mundo" à padaria comunitária. In: SEMINÁRIO INTERNACIONAL: Gestão da terra urbana e habitação de interesse social. Campinas: PUCCAMP/Instituto Pólis/ Lincoln Institute of Land Policy. 2000.

BAUMAN, Z. Comunidade: a busca por segurança no mundo atual. Rio de Janeiro: Jorge Zahar Editor, 2003.

BESSIN, M. Le temps, une question de pouvoir. Mouvements, Paris, n.2, jan./fev. 1999.

BONDUKI, N.; SAULE Jr., N. Habitat II: assentamentos humanos como tema global. In: (Org.) Habitat: as práticas bem-sucedidas em habitação, meio ambiente e gestão urbana nas cidades brasileiras. São Paulo: Nobel, 1996.

BOURDIEU, P. Efeitos de lugar. In: ria do mundo. 4.ed. Petrópolis: Vozes, 1998.

CALDEIRA, T. P. R. Cidade de muros: crime, segregação e 2000.

¿ CARVALHO, C. S. A. O mutirão por dentro. In: GITAHY, \& M. L. C.; LIRA, J. T. C. (Org.) Cidade: impasses e perspectivas. São Paulo: FAU/Annablume/FUPAM, 2007.

Lupa e telescópio - o mutirão em foco: São Paulo, anos 90 e atualidade. 2004. Dissertação (Mestrado em Arquitetura e Urbanismo) - Programa de Pós-Graduação $\bullet$ em Arquitetura e Urbanismo da FAU/USP. São Paulo, 2004 .

DAGNINO, E.: OLVERA, A. J.; PANFICHI, A. Para uma outra leitura da disputa pela construção democrática na América Latina. In: (Org.) A disputa pela constru丸 ção democrática na América Latina. São Paulo: Paz e Terra, 2006.

FELIPE, J. P. Mutirão e autogestão no Jardim São FrancisCo (1989-1992): movimento de moradia, lugar do arquiteto. 1997. Dissertação (Mestrado em Arquitetura) - Programa de Pós-Graduação em Arquitetura da EESC-USP. São Paulo, 1997.

FERRO, S. O canteiro e o desenho. São Paulo: Projeto IAB, 1977.

Notas sobre o vício da virtude. Novos Estudos $\overline{C E B R} A P$, São Paulo, n.76, nov. 2006
FORTUNATO, E. Os mutirões autogeridos como alternativa para a moradia popular: um exercício de cidadania? 2002. Tese (Doutorado em Geografia Humana) - Programa de Pós-Graduação em Geografia da FFLCH/USP. São Paulo, 2002

GUERRA, M. C. B. As ong's de assessoria a movimentos sociais por habitação. 1998. Tese (Doutorado em Sociologia) - Programa de Pós-Graduação em Sociologia da FFLCH/USP. São Paulo, 1998.

HARVEY, D. A produção capitalista do espaço. 2a. ed. São Paulo: Annablume, 2001.

LOPES, J. M. O anão caolho. Novos Estudos CEBRAP, São Paulo, n. 76, nov. 2006.

MEYER, R. M. P.; GROSTEIN, M.; BIDERMAN, C. São Paulo Metrópole. São Paulo: EDUSP/Imprensa Oficial do Estado, 2004.

OLIVEIRA, F. A economia brasileira: crítica da razão dualista. In: Seleções CEBRAP 1: Questionando a economia brasileira. São Paulo: Brasiliense/CEBRAP, 1976.

O Estado e a exceção - ou o Estado de Exceção? Estudos Urbanos e Regionais, São Paulo, v.5, n.1, maio 2003.

. O vício da virtude: autoconstrução e acumulação capitalista no Brasil. Novos Estudos CEBRAP, São Paulo, n. 74 , mar. 2006 .

PAOLI, M. C. O mundo do indistinto: sobre gestão, violência e política. In: OLIVEIRA, F.; RIZEK, C. S. (Org.) $A$ era da indeterminação. São Paulo: Boitempo Editorial, 2007.

PREFEITURA MUNICIPAL DE SÃO PAULO. Mapa $d a$ vulnerabilidade social da população da cidade de São Paulo: Zona Leste. São Paulo: PMSP/CEBRAP, 2005.

RANCIÈRE, J. O desentendimento. São Paulo: Editora 34, 1996.

RIZEK, C. S.; BARROS, J.S. Mutirões autogeridos: construindo e desconstruindo sociabilidades. In: FRÚGOLI JR, H.; ANDRADE, L. T.; PEIXOTO, F. A. (Org.) As cidade e seus agentes: práticas e representações. Belo Horizonte: Editora PUC Minas/EDUSP, 2006.

RONCONI, R. Habitações construídas com gerenciamento dos usuários, com organização da força de trabalho em regime de mutirão. 1995. Dissertação (Mestrado em Arquitetura) - Programa de Pós-Graduação em Arquitetura da EESC/USP. São Paulo, 1995.

SACHS, C. São Paulo: políticas públicas e habitação popular. São Paulo: EDUSP, 1999

SCHWARZ, R. Sequências brasileiras. São Paulo: Companhia das Letras, 1993.

TELLES, V. S.; CABANES, R. Nas tramas da cidade: trajetórias urbanas e seus territórios. São Paulo: Associação Editorial Humanitas, 2006.

WACQUANT, L. Os condenados da cidade: estudos sobre marginalidade avançada. Rio de Janeiro: Revan, 2001.

West Side story: um bairro de alta insegurança em Chicago. Margem Esquerda. São Paulo, v.8, nov. 2006.

ZALUAR, A. Crime, medo e política. In: ; ALVITO,

M. Um século de favela. 5.ed. Rio de Janeiro: Fundação Getúlio Vargas, 2006. 


\section{A SELF-MANAGED TASK FORCE AND THE CONTEXT OF THE DEMOCRATIC EXPERIENCE REVISITED}

\section{Edson Miagusko}

This paper is about the trajectories of the residents of a housing estate on the outskirts of Sao Paulo made by a self-managed task force. This task force occurred in the context of the democratic experience of the 80s. The hypothesis is that the forms of sociability and the trajectories of these residents, influenced by the discourse of autonomy and participation, are called into question: on the one hand, the possibility of invention, of the production of a house through an autonomous action and, on the other hand, the permeability of that experience to a certain sociability enclosed by the limits determined from outside and inside the its own set. To this end, we made a series of interviews and tried not to lose sight of the context that determines a reduced field of possibilities. This perspective enables one to collect not only the action of these movements, but also how the poorest of the city are organized to confront this social inequality produced in urban areas.

KEYwORDS: periphery, task force, urban social movements, housing, cities.

\section{LE TRAVAIL D'UN GROUPE D'ENTRE-AIDE AUTO-GÉRÉ ET LE CONTEXTE DE L'EXPÉRIENCE DÉMOCRATIQUE REVISITÉ}

\section{Edson Miagusko}

Cet article analyse la trajectoire des habitants d'un complexe résidentiel dans la banlieue de Sao Paulo réalisé par un travail d'entre-aide autogéré. Le travail de ce groupe d'entre-aide a été réalisé dans le contexte d'une expérience démocratique des années 80 . On part de l'hypothèse que les formes de sociabilité et les trajectoires de ces habitants, influencées par un discours sur l'autonomie et la participation, sont remises en question : d'une part la possibilité de créer, de construire sa maison à partir d'une action autonome et, d'autre part la perméabilité de cette expérience à une sociabilité enfermée dans des limites venant de l'extérieur et de l'intérieur de l'ensemble lui-même. Nous avons donc réalisé une série d'interviews et nous avons essayé de ne pas perdre de vue le contexte qui détermine un champ réduit de possibilités. Cette perspective a permis non seulement de saisir l'action de ces mouvements mais aussi la façon dont les couches de population plus pauvre de la ville s'organisent pour affronter les inégalités sociales produites dans les espaces urbains.

MoTS-CLÉs: périphérie, entre-aide, mouvements sociaux urbains, habitation, Villes.

Edson Miagusko - Professor Adjunto de Ciências Sociais da Universidade Federal Rural do Rio de Janeiro. Doutor em Sociologia pela Universidade de São Paulo. Pesquisador do Núcleo de Análise em Políticas Públicas (NAPP/UFRRJ) na linha de pesquisa cidades, política e sociabilidades urbanas onde desenvolve projeto de pesquisa sobre periferias urbanas e sobre os megaeventos esportivos. Tem experiência na área de Sociologia Urbana e Sociologia Política com atuação nos seguintes temas: movimentos sociais e sociedade civil, cidades e conflitos urbanos. Publicações recentes: Movimentos de moradia e sem-teto em São Paulo: experiências no contexto do desmanche. São Paulo: Alameda Editorial/FAPESP, no prelo, 2011; Entrevista: Unir os trabalhadores para construir algo novo. Correio Bancário, Vitória, p. 6 - 6, 02 abr. 2009. 